\title{
Radioisotope and chemical inhibitor measurements of dimethyl sulfide consumption rates and kinetics in estuarine waters
}

\author{
Gordon V. Wolfe ${ }^{1, *}$, Ronald P. Kiene $\mathrm{e}^{2, * *}$ \\ ${ }^{1}$ Dept of Microbiology, University of Washington SC-42, Seattle, Washington 98195, USA \\ ${ }^{2}$ University of Georgia Marine Institute, Sapelo Island, Georgia 31327, USA
}

\begin{abstract}
Microbial consumption rates of 1 to $20 \mathrm{nM}$ dimethyl sulfide (DMS) in estuarine wholewater samples from coastal Georgia (USA) were measured by 2 methods: production of radiolabeled $\mathrm{CO}_{2}$ and particulates $>0.2 \mu \mathrm{m}$ from $\left({ }^{14} \mathrm{CH}_{3}\right)_{2} \mathrm{~S}$, and specific inhibition by addition of $500 \mu \mathrm{M}$ chloroform. The combination and comparison of these 2 methods helped overcome some inherent limitations of each one, and both methods gave short turnover times ( $<1 \mathrm{~d}$ ) at low DMS concentrations ( 1 to $3 \mathrm{nM}$ ). DMS production was often as rapid as its consumption, suggesting very tight cycling. However, when exogenous DMS was added to increase concentrations, consumption rates saturated below $20 \mathrm{nM}$, suggesting high affinities for DMS. Kinetics and rates appeared similar over a several week period in samples taken from the Duplin River, a coastal tidal river where DMS concentrations were consistently in the range of 1 to $3 \mathrm{nM}$. In contrast, samples of water which had recently flooded the marsh had much higher DMS concentrations, but consumption rates were similar to those observed in the creek waters before they flooded the marsh. The turnover times calculated for the waters over the marsh were on the order of 3 to $7 \mathrm{~d}$. The radioisotope method showed that DMS assimilation into cell material was approximately equal to that respired as $\mathrm{CO}_{2}$ and confirmed $500 \mu \mathrm{MCHCl}_{3}$ as an excellent inhibitor of DMS consumption. However, it appears that chloroform may in some cases increase dissolved DMSP concentrations and hence DMS production, leading to overestimates of DMS consumption rates. Two other inhibitors of DMS consumption, dimethyl disulfide (100 nM) and dimethyl ether $(30 \mu \mathrm{M})$, gave similar but lower consumption rates compared to chloroform, and show promise as specific inhibitors for future studies.
\end{abstract}

\section{INTRODUCTION}

Dimethyl sulfide (DMS) is the most abundant reduced sulfur gas in marine surface waters, with global concentrations averaging $3 \mathrm{nM}$ (Cooper \& Matrai 1989). It provides an important natural flux of sulfur from the ocean to the atmosphere (Bates et al. 1991). It also appears that oxidized DMS may be the source of most natural sulfate aerosols in the marine troposphere which serve as cloud condensation nuclei, and which

\footnotetext{
Present addresses:

- College of Oceanic and Atmospheric Sciences, Oregon State University, Oceanography Administration Bldg 104 Corvallis, Oregon 97331-5503, USA

- Dept of Marine Sciences, University of South Alabama LSCB 25, Mobile, Alabama 36688, USA
}

may influence global climate via the modulation of stratus cloud albedo (Charlson et al. 1987). Therefore the natural cycling of DMS in marine waters affects the global sulfur cycle and possibly global climate.

DMS is produced biologically from several precursor compounds, primarily dimethylsulfoniopropionate (DMSP) which is synthesized by many species of micro- and macroalgae. However, the enzymatic conversion of DMSP to DMS is poorly understood and likely involves many members of the marine microbial food web. DMS sinks include photooxidation and seaair exchange, but microbial consumption may be the most important. Previous consumption rate measurements showed turnover times of $<1$ to $7 \mathrm{~d}$ in coastal and pelagic surface waters (Kiene \& Service 1991, Wolfe \& Bates 1993), compared to sea-air exchange times of weeks to months (Kiene \& Bates 1990), and 
it appears that only a small fraction of the DMS produced in the ocean may actually escape to the atmosphere (Kiene \& Service 1991, Wolfe 1992, Kiene 1993)

The goals of this study were to investigate microbial consumption of DMS in freshly collected estuarine water samples, including consumption rates, kinetics, and sensitivity to different compounds. A companion paper (Wolfe \& Kiene in press) examines the effects of many common substrates and low molecular weight compounds on DMS consumption rates. In this paper we combine and compare the radioisotope and chemical inhibitor methods for measuring DMS consumption rates and kinetics in whole-water samples from coastal Georgia, USA. The methods take different approaches to measuring DMS consumption, have contrasting strengths and weaknesses, and give somewhat complementary information about the consumption processes. The radiolabel approach measures gross conversion of DMS to labeled products such as $\mathrm{CO}_{2}$ and cell compounds. The inhibitor approach measures net DMS levels produced by the balance of production and consumption, and by selectively inhibiting DMS consumption, deduces both production and consumption rates.

\section{MATERIALS AND METHODS}

Sample location. Samples were collected from the Marsh Landing dock on the Duplin River, a tidal creek which separates Sapelo Island from mainland Georgia. Salinity was measured by refractometer and varied from 23 to $28 \mathrm{ppt}$ over the course of the study ( $6 \mathrm{wk}$ ) Water temperatures ranged from 27 to $31^{\circ} \mathrm{C}$, and ambient [DMS] from ca 1 to $3 \mathrm{nM}$. Surface water samples were collected at the upstream end of the dock directly into Teflon incubation bottles or into a $10 \mathrm{l}$ carboy with minimal agitation or bubbling, and were immediately taken to the laboratory and kept in the dark within $1^{\circ} \mathrm{C}$ of ambient temperature. Water in the carboy was gently stirred with a magnetic stirrer while removing water for incubation bottles, and all water transfers were performed to minimize agitation and loss of DMS.

Additional measurements were made on water taken from a small ( $1 \mathrm{~m}$ width) creek located in the upper Spartina alterniflora marsh adjacent to the laboratory. This creek was sampled on the flood tide after the water had flooded the marsh. This water was enriched in DMS and dissolved DMSP (DMSP $)$ relative to the waters flooding onto the marsh, which had similar DMS and DMSP concentrations to Duplin River water. This enrichment in upper marsh waters was probably due to DMSP leaching from $S$. alterniflora DMSP (Pakulski \& Kiene 1992).
Radioisotope incubations. UL $\left[{ }^{14} \mathrm{C}\right] \mathrm{DMS}\left(\left({ }^{14} \mathrm{CH}_{3}\right)_{2} \mathrm{~S}\right)$ was obtained from Amersham Co. (Arlington Heights, IL, USA). The stock was quoted at $96 \%$ purity in 1985 with specific activity of $22.3 \mathrm{mCi} \mathrm{mmol}^{-1}$. The standard was frozen on liquid nitrogen and then dissolved into sterile deionized water to a concentration of approximately $55 \mu \mathrm{M}$, about $1 \mathrm{nCi} \mu l^{-1}$ solution. Stock solutions were stored in serum vials stoppered with Mininert caps to avoid adsorption of DMS by rubber septa. DMS was the only sulfur gas detected by gas chromatography-flame photometric detector (GC-FPD). However, the stock solution had significant non-volatile radioactivity (10 to $20 \%$ ), as repeated spargings with $\mathrm{N}_{2}$ could not remove all radioactivity from solution. This nonvolatile fraction was rapidly metabolized and showed very different consumption kinetics and chloroform inhibition spectrum when degassed stock was added to whole water samples. Therefore, to avoid nonvolatile contaminants, ${ }^{14} \mathrm{C}$-DMS additions were taken from the headspace fraction with a gastight syringe after equilibration at room temperature $\left(21^{\circ} \mathrm{C}\right)$. Headspace specific activity was $21.9 \pm 1.7 \mathrm{mCi} \mathrm{mmol}^{-1}(\mathrm{n}=5)$. Because DMS has a partition coefficient of approximately 10 at typical room temperatures (Przyjazny et al. 1983, Dacey et al. 1984), the headspace radioactivity was approximately $0.1 \mathrm{nCi} \mu \mathrm{l}^{-1}$, and injection volumes were 20 to $500 \mu \mathrm{l}$ into $60 \mathrm{ml}$ water samples, for final concentrations of 1.4 to 35 $n{ }^{14} \mathrm{C}$-DMS

To estimate DMS consumption rates, additions of labeled DMS were kept as low as possible to minimize perturbation of consumption kinetics. However, because of the low specific activity and low concentrations required, true tracer experiments were not possible, and a kinetic approach utilizing 3 to 8 different ${ }^{14} \mathrm{C}$-DMS addition levels was adopted. Most additions were 1 to $10 \mathrm{nM}\left[{ }^{14} \mathrm{C}\right.$-DMS $]$, roughly in the range of in situ [DMS].

Incubations were conducted in $70 \mathrm{ml}$ serum bottles filled with $60 \mathrm{ml}$ of water and kept in the dark within $1^{\circ} \mathrm{C}$ of in situ water temperatures. Bottles were filled with as little aeration as possible to avoid degassing ambient DMS, and were crimp-sealed using Teflonlined septa (Supelco, Belefonte, PA, USA). Typically, 20 to 40 bottles were used per experiment, and filling took approximately $1 \mathrm{~h}$, at which time the labeled DMS was added. Therefore, some production or destruction of ambient DMS may have occurred in some bottles, but examination with GC-FPD of selected bottles showed that ambient DMS usually varied less than $30 \%$ between bottles. Inhibitors such as chloroform, if used, were added at least $0.5 \mathrm{~h}$ before the labeled DMS, to allow time for acclimation. Labeled DMS was added by syringe through the septum and the bottle shaken a few times vigorously to equilibrate, and the start time recorded. Typical incubations 
ran for 1 to $3 \mathrm{~h}$, timed to the minute. Bottles were incubated statically.

To stop biological activity, samples were killed by injection of $1 \mathrm{ml}$ formalin $10.6 \%$ final concentration formaldehyde). To prevent formalin carry-over from experiment to experiment, washed incubation bottles were subsequently muffled at $450^{\circ} \mathrm{C}$ for 2 to $4 \mathrm{~h}$. Tests showed that without this treatment consumption rates were significantly $(30 \%)$ lower, and autoclaving the bottles was not nearly as effective in preventing loss of consumption. Just before adding formalin, $1 \mathrm{ml}$ of solution was removed to count for total radioactivity as a check on the amount of ${ }^{14} \mathrm{C}$-DMS added to each bottle, and consumption activities were normalized to this number. Each ${ }^{14} \mathrm{C}$-DMS addition was usually conducted in duplicate, with typical bottle-to-bottle $\left[{ }^{14} \mathrm{C}\right.$ DMS] variations of $\pm 5 \%$. Each addition also used a control bottle which was killed at time zero and then incubated with the others to account for non-biological reactions and/or processing artefacts.

DMS consumption products recovered included labeled $\mathrm{CO}_{2}$ and particulates (cell material $>0.2 \mu \mathrm{m}$ ). Following formalin addition, the bottles were uncapped and $30 \mathrm{ml}$ was filtered for cell material. Polycarbonate membrane filters (Nuclepore $0.2 \mu \mathrm{m}$ ) recovered about $77 \%$ as much radioactivity as nitrocellulose filters (Millepore $0.22 \mu \mathrm{m}$ ). Time-zero killed samples showed no such trend, though variation was large due to low counts. Because of significant particulate loadings in the water samples, high vacuum pressures were required with membrane filters, possibly causing cell breakup and loss of signal; therefore, nitrocellulose filters were used for most incubations.

The remaining sample was capped with a rubber stopper fitted with a center-well cup (Kontes \#8823200000 ) filled with $0.15 \mathrm{ml}$ of $1 \mathrm{~N} \mathrm{NaOH}$, and the sample was acidified with $0.5 \mathrm{ml}$ of $1 \mathrm{~N} \mathrm{HCl}$ (final $\mathrm{pH} 2.5$ to 3) to convert $\mathrm{HCO}_{3}{ }^{-}$to $\mathrm{CO}_{2}$. The $\mathrm{CO}_{2}$ was degassed on a rotary shaker for $4 \mathrm{~h}$ at $125 \mathrm{rpm}$ and the cup+base counted for radioactivity. Bottles spiked with $\mathrm{H}^{14} \mathrm{CO}_{3}{ }^{-}$ were used to measure recovery of $\mathrm{CO}_{2}$; recoveries were typically 95 to $105 \%$. Time-zero fixed controls were used to adjust for the adsorption of residual ${ }^{14} \mathrm{C}$ DMS by the $\mathrm{NaOH}$, which was typically $1 \%$ of the total radioactivity. All samples were placed in suitable volumes (4 $\mathrm{ml}$ for filters, $8 \mathrm{ml}$ for $\mathrm{CO}_{2}$ and liquid samples) of Ecolume scintillation cocktail (ICN Biomedicals, Costa Mesa, CA, USA) and counted with a Beckman LS-7500 liquid scintillation counter. Quench corrections were made by external standards and the Beckman $\mathrm{H}$ Number method; counting efficiency over a wide range of quenching conditions was ca 87 to $93 \%$.

Several potential problems should be noted. The low DMS concentrations and activities used necessitated unusual care in the preparation, handling, and processing of samples, especially in the treatment of blanks. The use of phenethylamine, a standard organic base used for trapping labeled $\mathrm{CO}_{2}$, was found to adsorb residual ${ }^{14} \mathrm{C}$-DMS from the headspace, reducing the signal-to-noise ratio. $\mathrm{NaOH}$ was much more selective for $\mathrm{CO}_{2}$, and did not require a degas step to eliminate unreacted ${ }^{14} \mathrm{C}$-DMS. Also, the volume and strength of $\mathrm{NaOH}$ used in the trap was critical as too much base had a disruptive effect on the Ecolume scintillation cocktail. We found that $0.15 \mathrm{ml}$ of $1 \mathrm{~N} \mathrm{NaOH}$ could be counted in $8 \mathrm{ml}$ of cocktail and this amount of base was also manageable in the cup.

The fraction of radioactivity (normalized to the total radioactivity of each bottle) appearing as $\mathrm{CO}_{2}$ and particulates was summed to calculate consumption rates. Time-zero controls were used to correct for nonbiological processes and/or sampling artefacts such as adsorption of unreacted ${ }^{14} \mathrm{C}$-DMS onto filters or in $\mathrm{CO}_{2}$ traps. The fraction of label consumed was then multiplied by total [DMS] (in situ [DMS] plus label addition) to calculate total consumption rates.

Inhibition incubations. Inhibition incubations were conducted in $250 \mathrm{ml}$ Teflon bottles; we looked for but found no significant differences between these and $70 \mathrm{ml}$ serum bottles crimp-capped with Teflon septa. Bottles were filled almost completely with seawater to minimize loss of DMS to headspace. Duplicate bottles were prepared with and without additions of chloroform (Fisher, ACS grade, typically $10 \mu \mathrm{l}$ per $250 \mathrm{ml}$ bottle for final chloroform concentration of $500 \mu \mathrm{M}$ ). After addition, the bottle was gently inverted several times to dissolve the chloroform. However, it took up to $1 \mathrm{~h}$ for the chloroform to totally dissolve, possibly limiting its effect early in the incubation. Samples were incubated statically in the dark within $1{ }^{\circ} \mathrm{C}$ of in situ temperatures, usually for 6 to $12 \mathrm{~h}$.

Bottles were subsampled periodically (every 1 to $4 \mathrm{~h}$ ) for DMS concentrations which were analyzed by GC-FPD. Subsamples for GC analysis were typically 2 to $5 \mathrm{ml}$, depending on DMS concentrations, and samples were positive-pressure filtered gently through $\mathrm{GF} / \mathrm{F}$ glass fiber filters to remove particulate DMSP $\left(\right.$ DMSP $\left._{\mathrm{p}}\right)$. They were then sparged to remove DMS which was cryotrapped in liquid nitrogen, and finally injected for analysis. Detection limit was approximately $30 \mathrm{pg} S$ per sample, or about $0.5 \mathrm{nM}$ DMS per $2 \mathrm{ml}$ sample. Other sampling and GC details were described in Kiene \& Service (1991)

Calculation of DMS consumption rates was based on the assumption that chloroform selectively inhibits microbial DMS consumption without affecting its production or nonbiological sinks. Previous work (Kiene \& Service 1991, Kiene 1992) showed that chloroform does not appear to affect DMS production from dis- 
solved DMSP. However, the production of DMS occurs by several other potential pathways, including direct algal release, conversion of particulate DMSP (for example, on detrital material), and the effect of chloroform on these pathways is unknown. Assuming selective inhibition and minimal non-biological sinks, DMS production rates were calculated from a linear regression of [DMS] vs time in the chloroform amended bottles, and DMS consumption rates were calculated as the difference in slopes between the chloroform and unamended bottles. Using means from duplicate or triplicate bottles for each treatment, calculated linear regressions were usually good $\left(\mathrm{r}^{2}>0.9\right)$ over the sampling period. However, in some cases replicate variation was significant.

Other inhibitors (dimethyl ether, dimethyl disulfide) were treated similarly. Dimethyl ether $(99+\%$, Aldrich) was either added directly by gastight syringe or from a saturated solution to a final concentration of 20 to $50 \mu \mathrm{M}$. DMDS ( $99 \%$, Aldrich) was added from solution to a final concentration of approximately $100 \mathrm{nM}$. DMDS eluted well after DMS and did not interfere with analysis. Dimethyl ether and chloroform were concentrated enough to also produce chromatographic peaks and these were used to check that all bottles received equal treatments; however, we did not attempt to quantify the additions.

\section{RESULTS}

\section{Radioisotope experiments}

As with previous incubations (Wolfe \& Bates 1993), conversion of radiolabeled DMS to $\mathrm{CO}_{2}$ and cell material was linear with time (Fig. 1). Relative production of labeled $\mathrm{CO}_{2}$ and particulates ranged from 1:1 to 2:1, indicating that DMS was assimilated as a carbon source. Other potential degradation product fractions were not well quantified and may have been underestimated. Previous work (Wolfe \& Bates 1993) indicated that dissolved $(<0.2 \mu \mathrm{m})$ material might be produced from DMS consumption, but in the present study this was not a large or consistent component of degradation products. The radioisotope method also did not measure the production of volatile gases such as methane from DMS, but incubations with 2-bromoethanesulfonic acid (data not shown) indicated that methanogenesis did not appear to be a factor in DMS degradation in these waters. Other gases, which might be formed from the demethylation of DMS, such as methyl mercaptan, were never noted in chromatographic analyses. Chloroform was confirmed to be a good inhibitor, causing $95 \%$ inhibition at $100 \mu \mathrm{M}$ and nearly $98 \%$ inhibition at $1000 \mu \mathrm{M}$. Concentrations

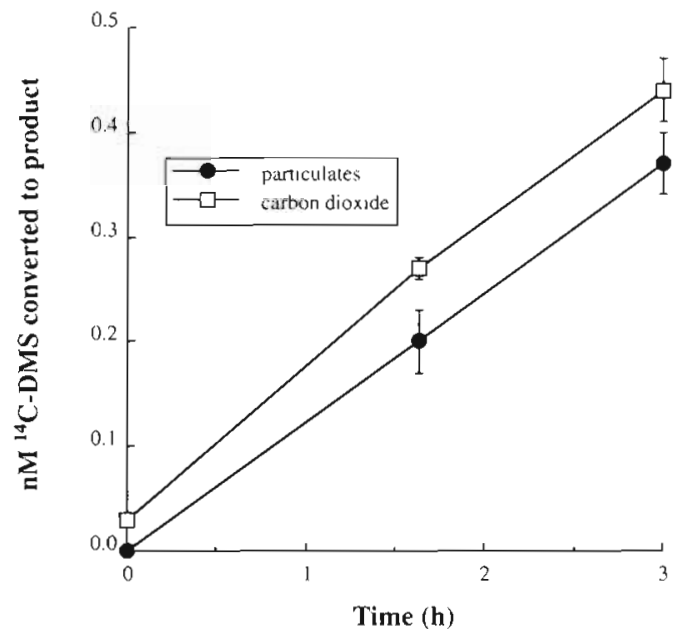

Fig. 1. Control run showning typical linear production of labeled particulates and $\mathrm{CO}_{2}$ over a $3 \mathrm{~h}$ period. Data are means of duplicates with standard deviations shown. Ambient [DMS] was $1.5 \mathrm{nM}$ and labeled additions were $1.4 \pm 0.2 \mathrm{nM}$

lower than $100 \mu \mathrm{M}$ gave variable but incomplete inhibition (Wolfe \& Kiene in press).

DMS consumption kinetics in Duplin River water showed very high substrate affinity and low $(<20 \mathrm{nM})$ saturation (Fig. 2a). Relative consumption fell from approximately $150 \% \mathrm{~d}^{-1}$ at minimal label additions (ca $1 \mathrm{nM}$ ) to only 20 to $50 \% \mathrm{~d}^{-1}$ at 20 to $30 \mathrm{nM}$ additions, giving turnover times from 0.8 to $4 \mathrm{~d}$ (Fig. 2b). Because of this pattern, in situ turnover rate was probably more rapid than indicated by the smallest addition of radiolabeled DMS. The very low signal-to-noise at the lowest additions [typically only a few hundred disintegrations per minute (dpm) above killed controls] also made extrapolation to in situ DMS levels difficult. Because of the low saturation, the kinetic behavior was often highly dependent on the exact in situ DMS concentrations. For example, Fig. 3a shows the calculated consumption rates assuming in situ [DMS] values of either $0.5 \mathrm{nM}$ or $1.5 \mathrm{nM}$, showing that the kinetic profile was very dependent on the exact DMS concentra-

Table 1. Kinetic parameters $\left(K_{\mathrm{s}}, V_{\mathrm{m}}\right)$ for DMS consumption in water from coastal Georgia during July 1992, measured by radioisotope incubations

\begin{tabular}{|lcccc|}
\hline Sample & Date & $\begin{array}{c}\text { [DMS] } \\
(\mathrm{nM})\end{array}$ & $\begin{array}{c}K_{\mathrm{s}} \\
(\mathrm{nM})\end{array}$ & $\begin{array}{c}V_{\mathrm{m}} \\
\left(\mathrm{nM} \mathrm{d}^{-1}\right)\end{array}$ \\
\hline Duplin River & 22 Jul 1992 & 0.5 & 0.8 & 4.2 \\
Duplin River & 25 Jul 1992 & 1.3 & 1.8 & 3.9 \\
Duplin River & 30 Jul 1992 & 3.1 & 7.6 & 20.8 \\
Marsh creek & 25 Jul 1992 & 7.2 & 40.6 & 12.1 \\
\hline
\end{tabular}



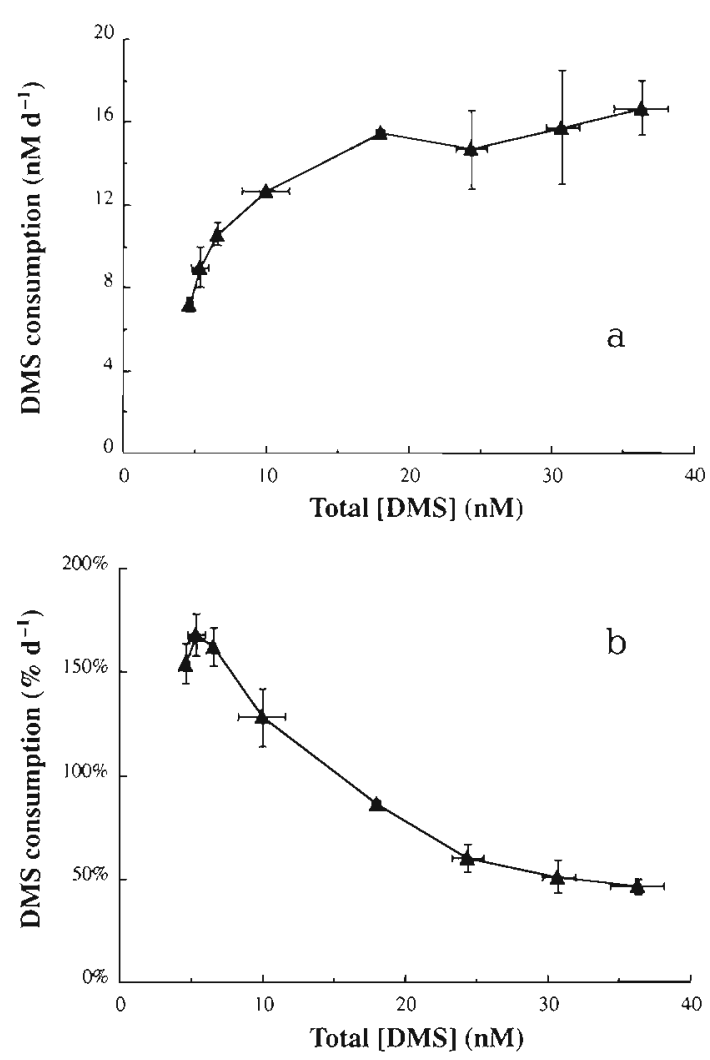

Fig. 2. Duplin River DMS consumption kinetics derived from ${ }^{14} \mathrm{C}$-DMS experiments: (a) consumption ( $\mathrm{MM} \mathrm{d}^{-1}$ ) vs total DMS concentration showing saturation near $20 \mathrm{nM}$; (b) turnover

$\left(\% \mathrm{~d}^{-1}\right)$ vs concentration. Points are means of duplicates

tions in the bottles. However, the relative turnover curves were much less sensitive (Fig. 3b). MichaelisMenten type kinetic parameters typically showed halfsaturation constants in the low nM range (Table 1).

Water samples from recently flooded marsh appeared to show different consumption kinetics than Duplin River water (Table 1). In situ [DMS) in the marsh stream was high (7.2 nM), and had a longer turnover time ( 3 to $7 \mathrm{~d}$ ) than Duplin River water ( 0.9 to 2 d; Fig. 4). These results for marsh water were from a single experiment, and may not have been representative of conditions on other occassions.

\section{Inhibition experiments}

As previously reported (Kiene \& Service 1991, Kiene 1992), unamended seawater samples showed considerable time-dependent variation in DMS concentrations during incubations, with some samples showing net consumption and others net production. Changes were approximately linear over the 4 to $8 \mathrm{~h}$ experimental time course. However, addition of
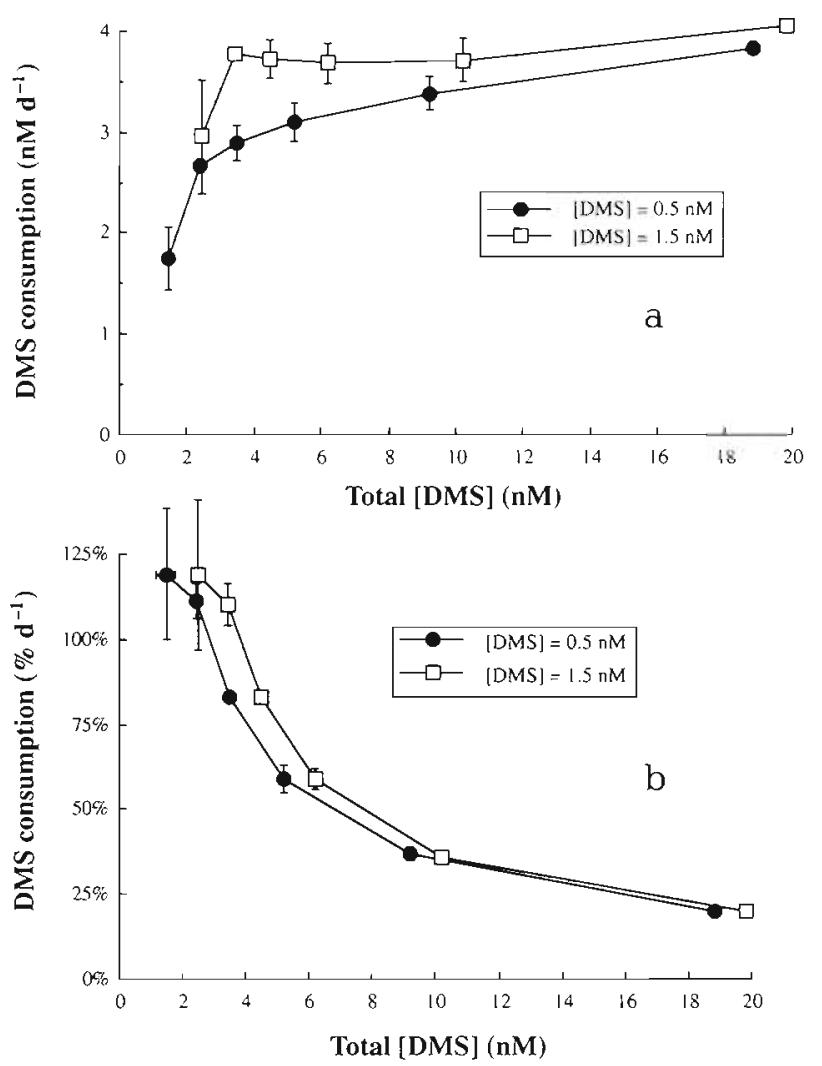

Fig. 3. (a) Kinetic curves and (b) turnover rate behavior for Duplin River sample showing sensitivity to in situ [DMS]. [DMS] was measured by GC in several samples at approximately $1.5 \mathrm{nM}(\square)$, but sample transfer could have reduced it below this in other incubation bottles. Curves are also shown. assuming in situ [DMS] was reduced to $0.5 \mathrm{nM}$

$500 \mu \mathrm{M}$ chloroform in all cases caused DMS to accumulate more rapidly than in untreated samples. Previous work (Kiene \& Service 1991, Kiene 1992) showed that chloroform did not change production of DMS from additions of dissolved DMSP, suggesting that chloroform selectively inhibited DMS consumption. However, comparisons of $500 \mu \mathrm{M}$ chloroform with several other inhibitors of DMS consumption, dimethyl ether ( $30 \mu \mathrm{M})$ and dimethyl disulfide (100 nM) (Wolfe \& Kiene in press) indicated that while these other 2 inhibitors gave very similar rate estimates, chloroform-derived rates were usually higher by about a factor of 2 (Fig. 5). The chloroform method (using $500 \mu \mathrm{M}$ chloroform) also consistently yielded turnover rate estimates which were also higher than those calculated from the radioisotope method by about a factor of 2 , both in this study period and in previous work (Wolfe \& Bates 1993). We therefore investigated the effects of $\mathrm{CHCl}_{3}$ on DMS and DMSP pools in greater detail. 

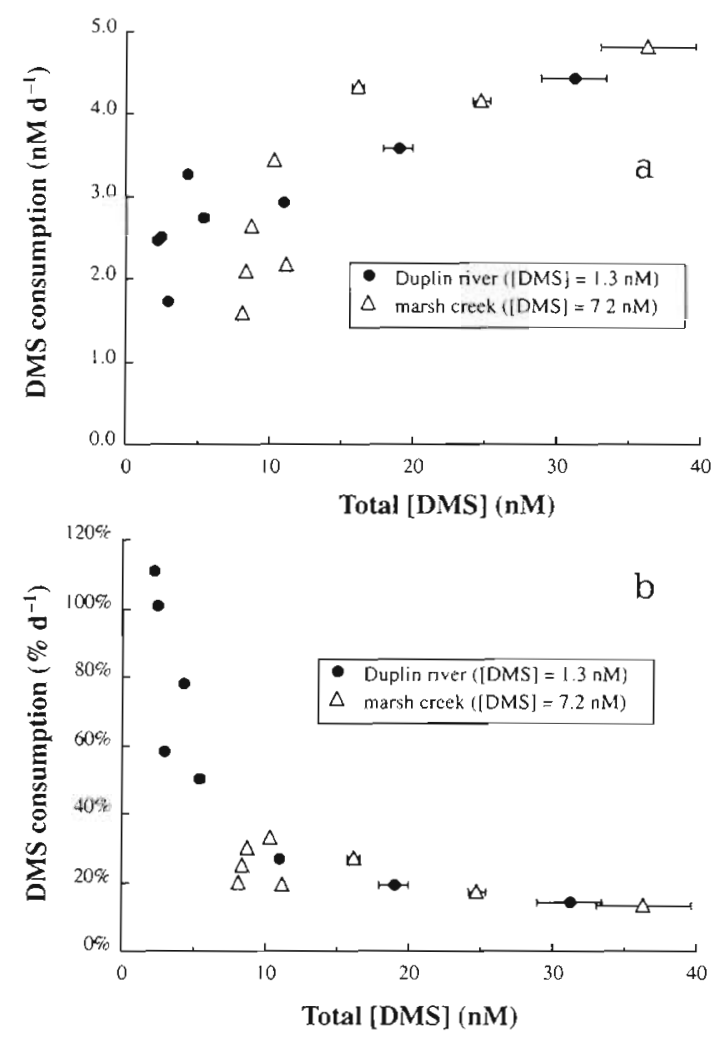

Fig. 4. Comparison of DMS consumption in Duplin River and marsh creek samples: (a) kinetics; (b) turnover rates

The accumulation of DMS in the bottles increased with the amount of chloroform added (100 to $1000 \mu \mathrm{M}$ ). The consumption rate estimates from this data (Fig. 6) increased with increasing $\mathrm{CHCl}_{3}$ concentration, but rates were very similar for 250 to $1000 \mu \mathrm{M}$ chloroform. Nonetheless, the higher accumulation rates with higher $\mathrm{CHCl}_{3}$ concentrations would not be expected if concentrations $>100 \mu \mathrm{M} \mathrm{CHCl}_{3}$ were completely effective at blocking DMS metabolism and if $\mathrm{CHCl}_{3}$ had no effects on DMS production processes. Experiments with ${ }^{14} \mathrm{C}$-DMS confirmed that chloroform was an effective inhibitor of DMS metabolism at concentrations above $100 \mu \mathrm{M}$ (Wolfe \& Kiene in press). Therefore, we suspected that $\mathrm{CHCl}_{3}$ might have caused some additional DMS production at the higher concentrations which would explain the increasing accumulation rates and why turnover rate estimates obtained using $500 \mu \mathrm{M} \mathrm{CHCl} 3$ were higher than those obtained with the radioisotope method.

An experiment conducted in October 1992 showed that DMSP $_{\mathrm{p}}$ concentrations decreased during the incubations in response to increasing levels of $\mathrm{CHCl}_{3}$ (Fig. 7). The decrease in the $500 \mu \mathrm{M} \mathrm{CHCl}_{3}$ treatment was, however, relatively small $(2.6 \mathrm{nM}$ out of a total of

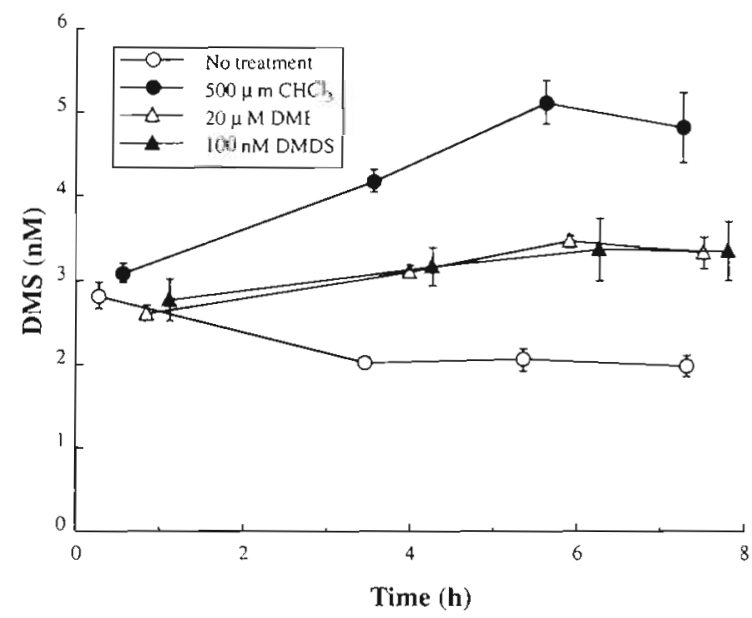

Fig. 5. Effects of chloroform $\left(\mathrm{CHCl}_{3}\right)$, dimethyl ether (DME), and dimethyl disulfide (DMDS) on DMS concentration. Experiment conducted 9 October 1992; water temperature was $20^{\circ} \mathrm{C}$. Samples were incubated at in situ temperature in the dark. DMS consumption rates calculated from slopes: chloroform: $9.8 \mathrm{nM} \mathrm{d}^{-1}$; dimethyl ether: $5.7 \mathrm{nM} \mathrm{d}^{-1}$; dimethyl disulfide: $5.1 \mathrm{nM} \mathrm{d}^{-1}$

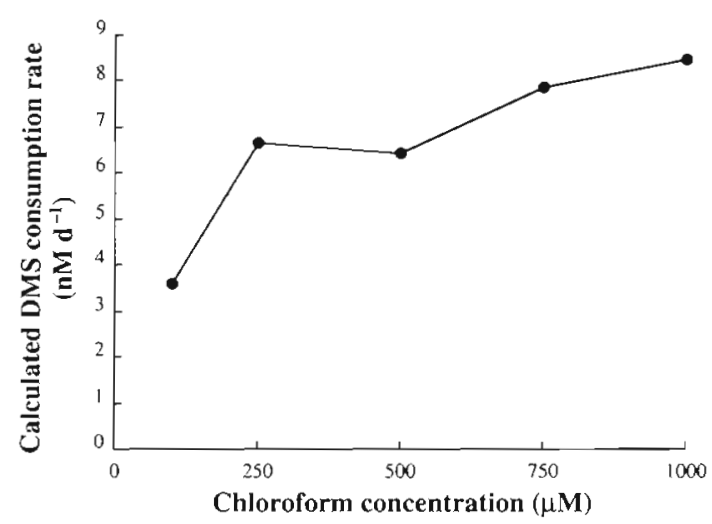

Fig. 6. Effect of different concentrations of $\mathrm{CHCl}_{3}$ on DMS consumption

47.1 nM DMSP, or $5.5 \%$ ). As expected, DMS accumulation rates increased with all the additions of $\mathrm{CHCl}_{3}$ (not shown). The $\mathrm{DMSP}_{d}$ data from this experiment suggested that $\mathrm{CHCl}_{3}$ caused some release of $\mathrm{DMSP}_{\mathrm{d}}$ but the trend was not clear because the sampling interval was too long and the increase appeared to be transient (not shown). A subsequent experiment with close interval sampling revealed that $500 \mu \mathrm{M} \mathrm{CHCl}_{3}$ caused a small, transient increase in $\mathrm{DMSP}_{\mathrm{d}}$ concentrations (Fig. 8), after which DMSP ${ }_{d}$ concentrations remained about $1.5 \mathrm{nM}$ higher in the $\mathrm{CHCl}_{3}$ treatment. DMSP $_{\mathrm{p}}$ levels were also decreased slightly by $500 \mu \mathrm{M}$ $\mathrm{CHCl}_{3}$ and the effect became more pronounced as the 


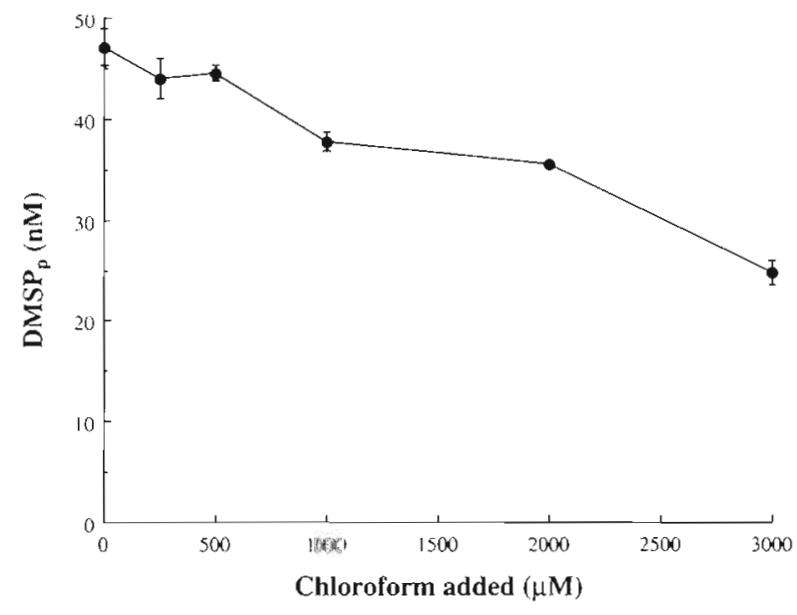

Fig. 7. Effect of increasing $\mathrm{CHCl}_{3}$ additions on particulate DMSP levels during $8.5 \mathrm{~h}$ incubations of whole-water samples. Initial [DMSP ] was $52 \pm 0.7 \mathrm{nM}(\mathrm{n}=3)$. Values shown are means and ranges of duplicates. Experiment conducted 9 October 1992 ; water temperature was $20^{\circ} \mathrm{C}$. Samples were incubated at in situ temperature in the dark.

incubation progressed. The effects of $500 \mu \mathrm{M} \mathrm{CHCl}_{3}$ on DMSP pools were difficult to observe; in 2 other such experiments, no significant effects of $500 \mu \mathrm{M}$ $\mathrm{CHCl}_{3}$ on DMSP pools were detected.

\section{DISCUSSION}

The radioisotope and chemical inhibition methods both provide rate estimates of DMS consumption, but each provides somewhat different information and is subject to errors and limitations. The radiolabel method traces the path of carbon, yielding information on the consumption products, but requires additions of the substrate which significantly perturb total DMS concentrations. The chloroform method requires the addition of an inhibitor which may not be completely selective, and which may promote the release of DMSP $_{\mathrm{d}}$.

The 2 methods probably give outer bounds of the consumption rates. The radioisotope method likely represents a lower bound because of (a) possible incomplete recovery of all DMS consumption products, and (b) the rapid decrease in turnover rates with even small additions of labeled DMS due to low saturation kinetics (Figs. $2 b \& 3 b$ ). In contrast, the chloroform amendment method gives an upper estimate because it appears to cause DMSP ${ }_{d}$ release which in turn stimulates DMS production. Comparison of $500 \mu \mathrm{M}$ chloroform additions with other effective inhibitors of DMS consumption such as dimethyl ether and dimethyl disulfide showed that $\mathrm{CHCl}_{3}$ gave

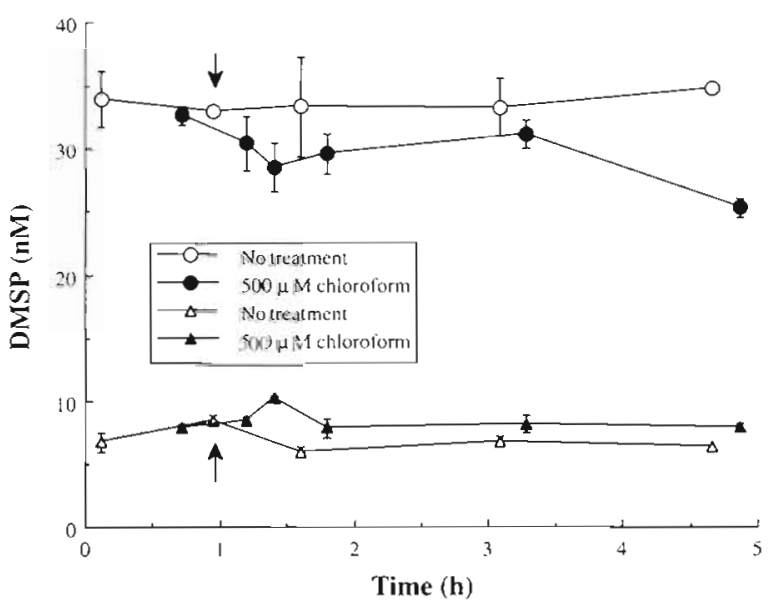

Fig. 8. Effects of chloroform on DMSP pools. Experiment conducted 18 November 1992; water temperature was $14.5^{\circ} \mathrm{C}$. Incubation was in 11 Teflon bottles at $15^{\circ} \mathrm{C}$ without shaking. Chloroform was added at time indicated by arrows, approximately $1 \mathrm{~h}$ into the experiment. Values shown are means and ranges of duplicates. Particulate and dissolved DMSP were defined by passage through a GF/F glass fiber filter, nominal retention size $0.7 \mu \mathrm{m}$. $0, \bullet \mathrm{DMSP}_{\mathrm{p}} \Delta, \Delta: \mathrm{DMSP}_{\mathrm{d}}$

higher rate estimates by about a factor of 2 (Fig. 5). This behavior was consistent for several other experiments (data not shown). The chloroform method also yielded approximately 2 -fold higher turnover rates than did the radioisotope method during the period of study. Despite the fact that the chloroform method appears to overestimate DMS consumption, it should be stressed that the general conclusions from previous studies which have used chloroform to inhibit DMS consumption (Kiene \& Bates 1990, Kiene \& Service 1991, Kiene 1992) are probably valid because the chloroform method approximates the estimates of other methods within a factor of about 2. Considering the limitations of tracer and inhibitor methods, consumption rates from both methods were in reasonable agreement and suggest very rapid microbial DMS consumption, with turnover times typically on the order of hours.

The radioisotope experiments showed that DMS consumption in Duplin River water appears to be due to one or more high affinity systems, exhibiting saturation below $20 \mathrm{nM}$, in the range of DMS concentrations normally found in these waters (Figs. 2a \& 3a). Because of this sensitivity, consumption rates were probably affected by additions of labeled DMS necessary to give minimal signal ( 0.5 to $1 \mathrm{nM}$ ), which significantly perturbed the in situ DMS concentrations ( 1 to $3 \mathrm{nM}$ ), and in situ turnover was probably more rapid than our lowest label addition indicated. Also, the kinetic curves generated were sensitive to small changes from bottle 
to bottle of the in situ DMS concentrations. Therefore, kinetic parameters such as the half-saturation concentrations (Table 1) should be viewed cautiously and this work is more useful for illustrating the general kinetic patterns than for calculating specific uptake constants.

Carbon dioxide and cell material appeared to be the major products formed from ${ }^{14} \mathrm{C}$-DMS, and were produced in roughly equal proportions in the short (1 to $3 \mathrm{~h}$ ) incubation times, indicating that DMS is used as a carbon and energy source. Previous experiments (Wolfe 1992, Wolfe \& Bates 1993) indicated that some fraction of the products may also be non-volatile dissolved material, but the non-volatile contaminant in the DMS stock noted here makes those results questionable, and they were in any case usually a minor fraction. Other artefacts such as cell lysis during acidification and filtration might also produce small amounts of dissolved radioactivity.

Over the 6 wk period of study, day-to-day kinetics were relatively consistent (Table 1), suggesting that rapid DMS consumption is a stable feature of the Duplin River system. This may be due to the relatively stable DMS concentrations, which were consistently between 0.5 and $5 \mathrm{nM}$. In many of the chloroform experiments, which measured DMS production as well as consumption, unamended samples appeared to be close to steady-state with respect to DMS cycling, although both production and consumption were rapid. When DMS was added to these samples, consumption usually increased as well, driving the system back towards equilibrium

Water samples from the flooded marsh, which experienced daily bursts of higher DMS concentrations (up to $10 \mathrm{nM}$ ) due to the leaching of DMSP from Spartina altemiflora leaves and its subsequent degradation to DMS (Pakulski \& Kiene 1992), showed different kinetic patterns than Duplin River water. Turnover times in the marsh were much longer ( 3 to $7 \mathrm{~d}$ vs 0.9 to $2 \mathrm{~d}$, Fig. $4 \mathrm{~b}$ ). It is possible that in the Duplin River, where concentrations of 1 to $3 \mathrm{nM}$ DMS are a consistent feature of the water chemistry, a relatively stable population of microbial DMS consumers is established. However, the DMS consumers in the marsh creek, exposed to sudden bursts of DMS received from waters flooding off the marsh, cannot adapt quickly enough to bring DMS concentrations down to levels as low as in the Duplin River.

The radioisotope method confirmed that $500 \mu \mathrm{M}$ chloroform is an excellent inhibitor of DMS consumption. However, the concentration of chloroform appears to be critical: concentrations lower than $100 \mu \mathrm{M}$ were not fully inhibitory, and concentrations higher than $500 \mu \mathrm{M}$ may disrupt other microbial processes, including DMS production (Figs. $6 \& 7$ ). This problem is compounded by the fact that chloroform is relatively insoluble in seawater (approximately $60 \mathrm{mM}$ ). Addition of $500 \mu \mathrm{M}$ chloroform required either vigorous shaking or a substantial delay (30 min) to achieve dissolution, both of which might affect its behavior in these short incubations. A survey of other potential inhibitors (Wolfe \& Kiene in press) indicated that $30 \mu \mathrm{M}$ dimethyl ether and 100 nM dimethyl disulfide both gave 90 to $95 \%$ inhibition of DMS consumption. These compounds are much more soluble than chloroform, and comparison of these compounds showed that both gave similar consumption rate estimates which were significantly lower than $500 \mu \mathrm{M}$ chloroform (Fig. 5), suggesting that chloroform may indeed cause increases in DMS production. These inhibitors may be more selective to DMS consumption and their evaluation in future experiments is warranted.

The kinetics of microbial DMS consumption are potentially critical to the global sea-air flux of DMS from the ocean, and its ultimate climatic effects. It appears that microbial consumption of DMS is one of its dominant sinks in the marine environment. Sea-air exchange turnover times are typically on the order of weeks to months, significantly longer than microbial consumption. Photochemical oxidation may be rapid enough to compete with biological consumption, but data are still scarce. If the low saturation kinetics for DMS consumption indicated by this work are shown to hold for open ocean waters, it would imply that unusual production episodes of DMS, as observed in blooms of high-DMSP-producing algae such as coccolithophorids (Keller et al. 1989) or Phaeocystis pouchetii (Gibson et al. 1990), might be critical to global seaair DMS flux. Rapid production of DMS could quickly saturate consumption activity and could cause lags in DMS consumption, allowing buildup of seawater DMS concentrations and other DMS sinks such as evacuation to the atmosphere to become much more significant. Further work is needed to extend these preliminary results to coastal and open ocean sites.

Acknowledgements. This work was supported by the NASA Earth Science and Applications Division, Interdisciplinary Research Program, and the National Science Foundation Grant OCE-88-17442 and OCE-92-03728. The University of Georgia Marine Institute very kindly provided housing at Sapelo Island for G.V.W. and Ghislain Gerard provided help with some of the DMSP experiments

\section{LITERATURE CITED}

Bates, T. S., Lamb, B. K., Guenther, A., Digon, J, Stoiber, R. E. (1991). Sulfur emissions to the atmosphere from natural sources. J. Atmos. Chem. 14: 315-337

Charlson, R. J., Lovelock, J. E., Andreae, M. O., Warren, S. G (1987). Oceanic phytoplankton, atmospheric sulphur, cloud albedo and climate. Nature 326: 655-661 
Cooper, W. J., Matrai, P. A. (1989). Distribution of dimethyl sulfide in the oceans. In: Saltzman, E. S. Cooper, W. J. (eds.) Biogenic sulfur in the environment. American Chemical Society, Washington, DC, p. 140-151

Dacey, J. W. H., Wakeham, S. G., Howes, B. L. (1984). Henry's law constants for dimethylsulfide in freshwater and seawater. Geophys. Res. Lett. 11: 991-994

Gibson, J. A. E., Garrick, R. C., Burton, H. R., McTaggart, A. R. (1990). Dimethylsulfide and the alga Phaeocystis pouchetii in Antarctic coastal waters. Mar. Biol. 104: 339-346

Keller, M. D., Bellows, W. K., Guillard, R. R. L. (1989). Dimethyl sulfide production by marine phytoplankton: an additional impact of unusual blooms. In: Casper, E. M., Bricelj, V. M., Carpenter, E. J. (eds.) Novel phytoplankton blooms. Springer-Verlag, Berlin, p. 101-115

Kiene, R. P. (1992). Dynamics of dimethyl sulfide and dimethylsulfoniopropionate in oceanic water samples. Mar. Chem. 37: 29-52

Kiene, R. P. (1993). Microbial sources and sinks for methylated sulfur compounds in the marine environment. In: Kelly, D. P., Murrell, J. C. (eds.) Microbial growth on C1 compounds. Intercept Ltd, Andover, p. 15-36

Kiene, R. P., Bates, T. S. (1990). Biological removal of dimethyl sulfide from seawater. Nature 345: 702-705

This article was submitted to the editor
Kiene, R. P., Service, S. K. (1991). Decomposition of dissolved DMSP and DMS in estuarine waters: dependence on temperature and substrate concentration. Mar. Ecol. Prog. Ser. 76: 1-11

Pakulski, J. D., Kiene, R. P. (1992). Foliar release of dimethylsulfoniopropionate from Spartina alterniflora. Mar. Ecol. Prog. Ser. 81. 277-287

Przyjazny, A., Janicki, W., Chrzanowski, W., Staszewski, R. (1983). Headspace gas chromatographic determination of distribution coefficients of selected organosulphur compounds and their dependence on some parameters. J. Chromatogr. 280: 249-260

Wolfe, G. V. (1992). The cycling of climatically active dimethyl sulfide (DMS) in the marine euphotic zone: biological and chemical constraints on the flux to the atmosphere. Ph.D. thesis, University of Washington, Seattle

Wolfe, G. V., Bates, T. S. (1993). Biological consumption of dimethyl sulfide (DMS) in the marine euphotic zone: results of radioisotope experiments. In: Oremland, R. S. (ed.) The biogeochemistry of global change: radiatively active trace gases. Chapman and Hall, New York, p. 691-703

Wolfe, G. V., Kiene, R. P. (in press). Effects of methylated, organic, and inorganic substrates on microbial consumption. of dimethyl sulfide in estuarine waters. Appl. environ. Microbiol.

Manuscript first received: February 8, 1993

Revised version accepted: June 16, 1993 